\title{
OBITUARY
}

\section{THOMAS MUIR JOHNSTONE}

Professor T. M. Johnstone died on 11 January 1983 in the Queen Elizabeth Hospital, Gateshead, after a brief illness. He would have been 59 on 18 January.

Johnstone was born in 1924 in Broughty Ferry near Dundee, Scotland, where he attended the local Grove Academy. He showed early linguistic promise and was quickly taking French, German, Latin and Greek in his stride. After the outbreak of war in 1939 the Dundee area saw an influx of Polish servicemen and the young schoolboy was drawn closely into the Polish service community. With his gift for languages and his quick ear, he soon picked up their language. This experience was to have a profound effect on him throughout his life. Despite other numerous linguistic distractions, he always retained a special place in his heart for Polish. He spoke it at every available opportunity and always regarded it as one of the languages with which he coped best.

Johnstone's meeting in Dundee with David Cowan while still a schoolboy was to have an even more profound effect on his life, however. The connexion with Arabic was established. One wonders what better ambassador of the language could have been found for this enthusiastic young man. Of all the languages which Johnstone might have selected and pursued to the highest possible level of attainment, it was Arabic that he was eventually to choose.

Despite his outstanding linguistic achievements at school, the harsh economic realities of war led Johnstone along a totally different path. His father, the owner of a small business, had been called up into the RAF and the luxury of a university education in languages was not at that time to be contemplated. He settled for the study of economics and enrolled at the School of Economics in Dundee for a London external B.Com. degree. He graduated in 1944, and, armed with a degree in economics, entered the employ of ICI in Manchester, a company for which he was to work until 1957 . He was always reticent regarding this period of his life and I was never able to discover whether he really enjoyed his work in industry. He nevertheless appears to have been a competent servant of the company and certainly showed great skill at reading the vicissitudes of the stock market and of financial investment in general.

Manchester had its compensations. He met there and married in 1949 a young nurse named Bernice Jobling. He found too that the city provided fulfilment for many of his intellectual cravings. Because of his wife's occupation, many of his leisure hours outside work had to be spent alone and he needed little prompting to enrol for educational classes. Of those available he chose Hebrew and began to learn both the classical and modern language under Arie Rubinstein, who had the reputation of charging for his services according to the means of his pupil. Johnstone soon proved to be such a promising find that his fees were waived altogether. Much stimulated by this Semitic language, he began to pick up his Arabic again. With his wife still working long and unsocial hours, he decided to register for an external London degree in Arabic and Hebrew. ICI were sympathetic and helpful and he was allowed time off work for study. His presence in Manchester also brought him into contact with a number of scholars who all had an influence on his life. The late Professor James Robson he found extremely kind, interested in him as a person as well as in his work. For Professor Charles Beckingham too, whom he met at this time, he felt the same depth of gratitude. He not only assisted Johnstone all he could with the 


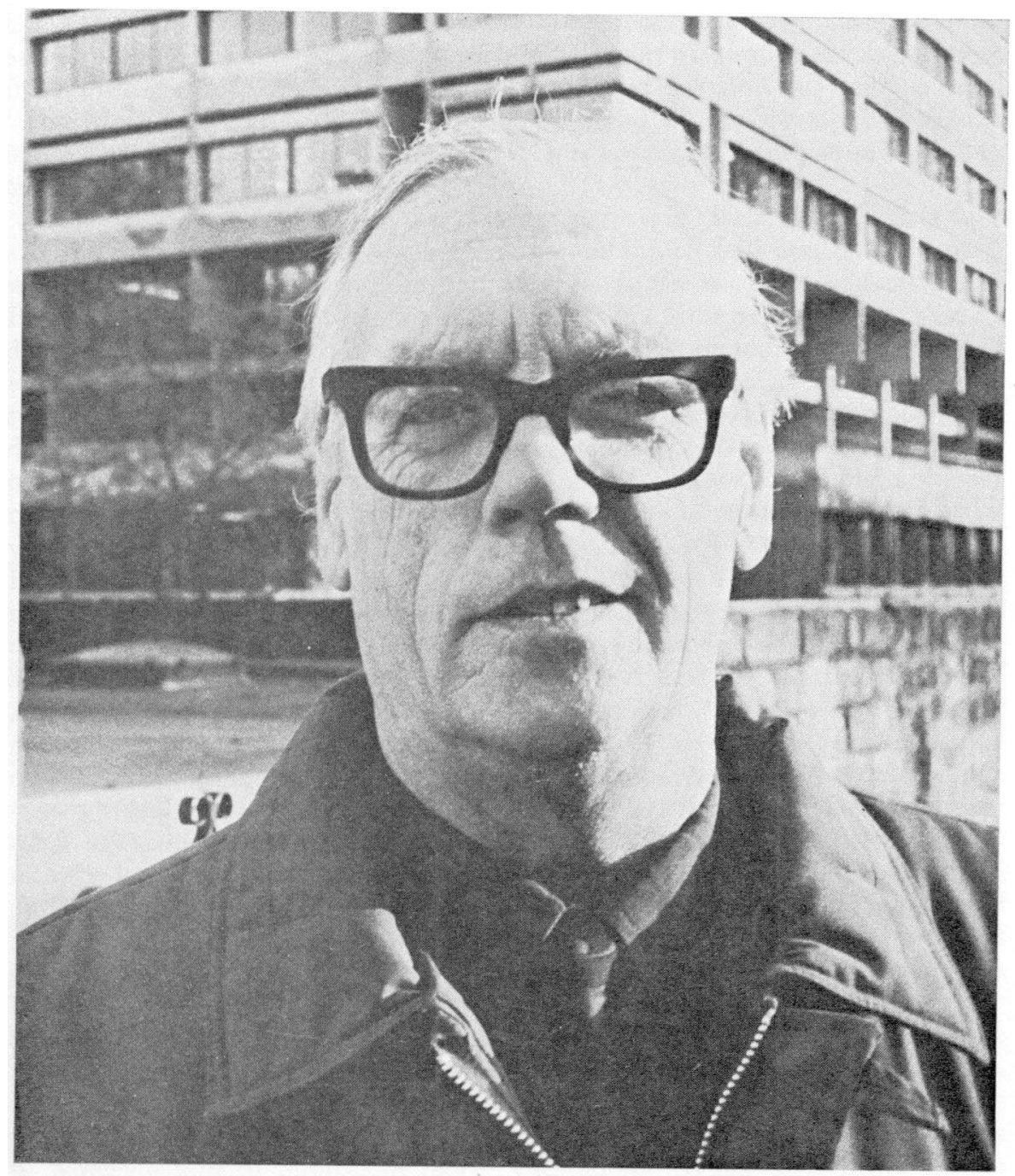

Thomas MUir Johnstone

BSOAS. XILII] 
rigours of an external degree, but was also to remain a life-long friend, the one responsible for urging him to contemplate a career in the academic world. All the hard work was amply rewarded in 1954 when, having dropped Hebrew after Intermediate level, Johnstone was awarded a London 1st class external honours degree in Arabic. Unfortunately, the scholarship offered at this point to enable him to go into full-time research fell short of being sufficient to support a family and he continued for the time being with ICI. Again with much encouragement from Professor Beckingham, Johnstone published his first scholarly article, 'An early manuscript of Ya'kūbī's Tărīkh', JSS, 1957, II, 189-95. The golden opportunity finally arrived and in 1957 he was appointed Lecturer in Arabic in the School.

The next thirteen years saw remarkable progress in his career. His first task after his appointment was to decide on a doctoral topic. Dialectology, I suspect, was never in doubt, but it was in great part due to the wisdom and foresight of Professor R. B. Serjeant, then holding the chair of Arabic at the School, that he developed the idea of a Gulf specialization. A frantic period lay ahead. Much work was necessary for this newly appointed teacher of Arabic and the chosen subject for his Ph.D. thesis, the dialects of Eastern Arabia, meant many long, difficult months of field-work. In 1962, six years after taking up his appointment, he was awarded the Ph.D. degree. Another three years brought further reward in the form of a readership in 1965. In 1970, after spending only thirteen years on the staff of the School, Johnstone was appointed to the chair of Arabic. He remained in this position until September 1982 when he decided to take early retirement. Some time before this his wife and the two unmarried members of the family had moved to Whickham near Newcastle-upon-Tyne to live and Johnstone commuted between Malet Street and Whickham. In the summer of 1982 he moved up to the North-East. Early retirement, he was determined, was not going to be the end of academic involvement. He had a great desire to continue the stimulating task of post-graduate supervision, as well as his own research programme. His move to the North-East brought him within easy range of Durham and its university. Here he and his wife were quickly accepted into the university community. To the delight of them both, he was appointed an Honorary Fellow in the School of Oriental Studies in the Michaelmas term of 1982. During his last illness he left instructions for his valuable library of oriental books, manuscripts, etc., to be donated by his family to the Durham University Library.

From the time of his first article published in 1957, Professor Johnstone maintained a constant supply of publications of the highest academic merit. He was a firm believer that one could only achieve genuine scholarship if one wrote what one wanted to write. He accordingly resisted the attempts of others to persuade him to publish in more 'prestigious' fields. His heart was in dialectology and it was in this field in which he made his first major scholarly contributions. His thesis was revised and published in the London Oriental Series (Vol. 17) as Eastern Arabian dialect studies, Oxford, 1967. What greater accolade could there have been in recognition of the importance of this work than its translation into Arabic by the Saudi scholar, Ahmad Muhammad al-Dubayb (Dirāsāt fī lahajāt sharq̄̄ 'l-Jazīrah al-'Arabiyyah, Riyadh, 1975) ? Numerous articles, in the main on Peninsula dialects, were published too. These appeared in the Bulletin and also in the Journal of Arabic Linguistics, of which Johnstone was a member of the editorial board. But his several visits to Oman, a country for which he had a particularly deep affection, from the 1960 s also opened up new horizons. Here he encountered a whole series of Semitic 
languages scarcely touched by solid academic research. Here were opportunities not to be missed. Here began his long love affair with the M(odern) S(outh) A(rabian) languages, Mehri, Harsūsi, Soqoțri and Jibbāli. Here he could find linguistic and intellectual satisfaction for himself and at the same time provide the world of science with acceptable academic descriptions of these Semitic languages. Here too were languages being daily swamped by the relentless advance of Arabic, languages dying before one's very eyes which had at all costs to be recorded. Further long absences in Oman in order to carry out field-work were necessary and the first fruits of these labours appeared in 1977 with the publication of his Harsüsi lexicon and English-Harsüsi word list with OUP. The larger Jibbaili lexicon followed (Oxford, 1981) and it has been discovered that his true opus magnum, a Mehri lexicon was already in publishable state when he died. He had clearly assembled much material in the shape of folk-tales in several of the MSA languages. There is lexical material on the Soqotri language too and it was his evident intention to publish a Soqotri lexicon. Professor Johnstone's publications over the years included many on the folk legends and tales of the Arabian Peninsula. In these articles, published in the main in Arabian Studies, he delighted in comparisons with similar material from vastly different corners of the globe, comparisons he was able to make only by dint of his unique linguistic ability over such a broad spectrum.

It is impossible in a few words to sum up adequately Tom Johnstone's achievements in the world of scholarship. The meticulous care with which he presented such high quality linguistic material was a revelation and a lesson to all those who read it. In the field of Arabic dialectology, it seems to me, his major contribution has been to raise its very status in Britain. Unlike some European countries, Britain has for far too long regarded dialects as the Cinderella of Arabic studies as a whole. Johnstone had begun to change this view, through his own writings and through his scholarly influence on his students. There is a further difficulty here too. There remains the feeling among certain Arabs-though their number is few and they are not those of the Peninsula, as Johnstone was always quick to point out that there is something distinctly sinister in Arabic dialect studies, that the study of the numerous dialects of Arabic helps in some way to fuel political ideas in the West of "divide and rule'. The Arabic language is one, is the cry. Johnstone never let such views upset or deter him. If his death leaves a gaping hole in Britain in Arabic dialect studies, it is impossible to estimate the blow which has been dealt to the study of the MSA languages world wide. It is impossible too at present to see how the situation might begin to be remedied, other than by the publication as speedily as possible of his material which has survived.

In the University Johnstone served between 1970-72 as the Chairman of the Board of Studies in Oriental and African languages and literatures. During the years 1973-75, he was Chairman of the Middle East Centre. From 1970 he had been an invaluable member of the editorial board of the Cambridge History of Arabic Literature. He was an editor of the journal, Zeitschrift für arabische Linguistik and a member of the Board of Trustees of the University of San 'a', Yemen Arab Republic. He was a member of the committee of the AngloOmani Society and of the steering committee of the Seminar for Arabian Studies.

Johnstone appreciated all good literature and, although this is not always apparent from his publications, he spent a very great deal of his time in its study. He was particularly fond of poetry (he wrote poetry himself) and Arabic literature offered him a rich supply. He read much in the field of pre-Islamic poetry which was perhaps his favourite, though good Arabic poetry of all periods 
enthralled him. He often expressed to me a great sense of disappointment at his having been born without what he termed ' a feeling for history'. But he would console himself with the belief that the key to the door of the edifice of any culture is the language of that culture.

Of the languages other than Polish, Hebrew and Arabic, those which commanded most of his attention were Russian, Greek of all periods, Icelandic and the Celtic languages. Russian was a natural extension of his interest in Polish. Homeric and classical Greek he had started as a boy and his library of Greek literature contains a number of texts used during his schooldays, all remarkably maturely annotated. The Icelandic sagas provided him over the years with much satisfying material and one of the major joys of his life was his visit to Iceland in 1970. He was too, very much a Celt and Gaelic, Irish, Welsh, Cornish and Breton all commanded his attention.

Tom Johnstone was an extremely caring teacher of undergraduates and a kind and thorough supervisor of research students. When dealing with the former, he was not content just to teach well, for the whole of the academic and personal welfare of the student was very much his concern, while the many postgraduate students who had the benefit of his attention will, I am sure, bear witness to the very special care which they received at his hands. To his family, colleagues, students and friends, as well as to the world of scholarship, Tom Johnstone's death is a great loss.

Rex SMITH 